\title{
Current states of opinion and future directions on the epidemiology of sex differences in human pain
}

\author{
Jacob M Vigil PhD
}

\begin{abstract}
JM Vigil. Current states of opinion and future directions on the epidemiology of sex differences in human pain. Pain Res Manage 2011;16(5):317-319.

One of the most commonly neglected findings in the human pain literature is the observation of sex differences in the mechanisms that support the phenotypic expression of pain. The present commentary describes an assessment of the prevalence of observed sex differences in various pain processes, and of how expert pain researchers interpret the epidemiology and, hence, the proximate and ultimate causes of such differences. Forty-two pain investigators completed an anonymous survey on the epidemiology of sex differences in the human pain experience. Investigator responses indicated that sex differences are pervasive across various areas of pain research, that sex differences are particularly pronounced in the area of situational influences on pain behaviors, and that contemporary pain researchers largely disagree on the epidemiology of, and hence, proximate and ultimate causes of the differences. The relevance of social situational factors on sex differences in pain behaviours is discussed in the context of evolutionary, developmental, social psychology and pain sensory systems that may function, in part, for regulating interpersonal intimacy.
\end{abstract}

Key Words: Epidemiology; Evolutionary psychology; Pain behaviours; Sex differences

$\mathrm{O}$ ne of the most commonly neglected findings in the human pain iterature is the observation of sex differences in the mechanisms that support the phenotypic expression of pain (1-5). This was evident at the recent 8th International Symposium on Pediatric Pain, held in in Acapulco, Mexico, where several researchers highlighted evidence of sex differences in various physiological (eg, nociceptive) and psychological (eg, verbal and nonverbal expressive) pain processes, only to refrain from attempting to explain the reason for their findings. As a recent convert to pain research, I found these reactions to be somewhat curious, particularly given my training in evolutionary, developmental psychology, which often prioritizes sexual dimorphisms as a valuable source of information for understanding the epidemiology and ontogenetic underpinnings of distress reactions that are differentially expressed in males versus females.

On my return from the conference, I decided to conduct a more thorough assessment of the prevalence of observed sex differences in various pain processes, and of how expert pain researchers interpret the epidemiology and, hence, proximate and ultimate causes of such differences. It was my hope that these assessments could serve as both a historical scientific archive and as an outline of the likely future directions that contemporary pain researchers may pursue in their investigation of this biological paradox.

\section{Respondent characteristics}

\section{METHODS AND RESULTS}

An anonymous survey was sent to each of the research presenters at the 8th International Symposium on Pediatric Pain for which contact information was available. In total, 42 investigators $(25 \%$ of the

\section{Létat actuel des opinions et des futures orientations sur l'épidémiologie des différences de la douleur selon le sexe chez les humains}

Les différences des mécanismes qui appuient l'expression phénotypique de la douleur selon le sexe font partie des observations les plus négligées dans les publications sur la douleur chez les humains. Le présent commentaire contient la description d'une évaluation de la prévalence des différences observées selon le sexe dans divers processus de douleur ainsi que de la manière dont les chercheurs dans le domaine de la douleur interprètent l'épidémiologie et, par conséquent, la cause proche et finale de ces différences. Quarante-deux chercheurs dans le domaine de la douleur ont rempli un sondage anonyme sur l'épidémiologie des différences selon le sexe dans l'expérience de la douleur chez les humains. D'après leurs réponses, les différences selon le sexe sont omniprésentes dans les divers secteurs de la recherche sur la douleur et sont particulièrement prononcées sur le plan des influences situationnelles sur les comportements relatifs à la douleur. Ces réponses démontrent également que les chercheurs contemporains dans le domaine de la douleur ne s'entendent pas sur l'épidémiologie des causes proches et finales des différences. La pertinence des facteurs situationnels sociaux sur les différences des comportements relatifs à la douleur selon le sexe est abordée compte tenu de la psychologie évolutive, développementale et sociale et des systèmes sensoriels de la douleur qui peuvent fonctionner, en partie, pour réguler l'intimité interpersonnelle.

solicited respondents) from various professional disciplines responded to the survey. Seventy one per cent of the participating respondents had PhDs/MDs (mean [ \pm SD] age $41.4 \pm 11.7$ years; 30 females), and most of the respondents assumed multiple professional roles $(55 \%$ health care practitioners, $82 \%$ research investigators $[10 \%$ basic human research, $5 \%$ basic animal research and $67 \%$ applied research] and $2 \%$ patient advocates).

Prevalence of observed sex differences

Table 1 shows the respondents' areas of pain research, years of experience investigating pain, and personal observations of, and known effect sizes of sex differences in their respective pain laboratories. Ninety-one per cent of the respondents were aware of sex differences in the broader pain literature, and the magnitude of personally observed effect sizes ( $66.7 \%$ of respondents) was positively correlated with the number of years investigating pain $(\mathrm{r}=0.34)$. Thus, it appears that with increasing research experience, the respondents became more mindful of the extent of said differences. Interestingly, investigators of situational-related pain factors reported an average observed effect size that was $32 \%$ higher than the average reported effect sizes across the remaining 11 research categories (an interpretation of the importance of situational context on the expression of pain will be presented in the Discussion section).

Importance of sex differences in pain

When asked about their personal views (coded 1 to 5 , from 'extremely untrue' to 'extremely true') on the importance of research on sex differences in pain, the vast majority of the respondents reported (by

University of New Mexico, Albuquerque, New Mexico, USA

Correspondence: Dr Jacob M Vigil, Department of Psychology, University of New Mexico, 1 University of New Mexico, MSC03 2220,

Albuquerque, New Mexico 87131-1161, USA. Telephone 505-277-0374, fax 505-277-1394, e-mail vigilj@unm.edu 
TABLE 1

Respondents' areas of research, pain-related experience, observed sex differences and average effect sizes of observed differences $(n=42)$

\begin{tabular}{|c|c|c|c|c|}
\hline Research area & Respondents, n (\%) & $\begin{array}{c}\text { Mean experience, } \\
\text { years }\end{array}$ & $\begin{array}{l}\text { Respondents that personally } \\
\text { observed sex differences, } \%\end{array}$ & $\begin{array}{c}\text { Personally observed } \\
\text { effect sizes }\end{array}$ \\
\hline Patient care & $25(60)$ & 14 & 68 & 1.2 \\
\hline Pharmacological treatment & $21(50)$ & 14 & 62 & 1.2 \\
\hline Nonpharmacological treatment & $28(67)$ & 13 & 71 & 1.4 \\
\hline $\begin{array}{l}\text { Physiology (nociception, afferent feedback, } \\
\text { brain activity) }\end{array}$ & $6(14)$ & 16 & 83 & 1.0 \\
\hline Perception & $12(29)$ & 10 & 80 & 1.3 \\
\hline Cognition & $10(24)$ & 10 & 80 & 1.3 \\
\hline Emotion & $17(41)$ & 11 & 88 & 1.5 \\
\hline Nonverbal behaviours & $18(43)$ & 11 & 67 & 1.1 \\
\hline Verbal behaviours & $15(36)$ & 13 & 73 & 1.1 \\
\hline Coping & $18(43)$ & 11 & 89 & 1.5 \\
\hline Experiential factors & $11(26)$ & 14 & 73 & 1.4 \\
\hline Situational factors & $12(29)$ & 11 & 92 & 1.9 \\
\hline
\end{tabular}

The majority of investigators assumed multiple areas of pain research across the supplied categories. Years of experience (mean [ \pm SD] $11.8 \pm 9.8$ years) was measured by asking: "How many years have you been practicing in your profession since you earned your highest degree?" Personally observed sex differences and statistical effect sizes of observed differences were measured by asking the following questions: "Have you observed sex differences in ANY of the pain mechanisms (eg, physiological, psychological, or behavioral) that you personally investigate?" (coded 0 and 1 for no and yes responses, respectively), and "What is the statistical effect size of the sex differences that you have observed?" (coded 0 to 3 , from not observed to statistically large)

either indicating 'true' or 'extremely true') that sex differences in pain mechanisms are 'important areas of scientific investigation' (91\%), that sex differences have 'important applied/practical significance' (88\%), that investigations of why sex differences exist will 'directly contribute to advancements in basic pain systems' (83\%), and that said investigations will 'directly contribute to advancements in pain management' (74\%). Only a minority of the respondents supported the view (by either indicating true or extremely true) that adequate theoretical attention (26\%) and that adequate empirical attention (24\%) 'have already been devoted to understanding sex differences in pain mechanisms'. The view that adequate empirical attention 'has already been devoted to understanding sex differences in pain' was held by a greater proportion of female investigators $(33 \%)$ compared with male investigators $(0 \%[\mathrm{P}=0.03 ; \mathrm{d}=0.66])$.

Nature of sex differences in pain

As for the nature of the phenomena, few researchers believed that sex differences are partly the result of maladaptive (flawed or damaged) pain mechanisms in males or females $(16.7 \%)$, whereas slightly more than one-half of the respondents $(57.1 \%)$ believed that sex differences 'are partly the result of adaptive (specialized and functional) pain mechanisms'. Additionally, $73.8 \%$ of the respondents believed that the differences 'are partly the result of exposure to different stressors'; $80.9 \%$ believed that the differences 'are partly the result of learned customs' (ie, culture), and $57.2 \%$ believed that the differences 'are partly the result of evolved pain systems'.

\section{DISCUSSION}

Some of the respondents' inferences, such as females being exposed to greater numbers of lifetime stressors than males, are not supported by the empirical literature (6). Likewise, the inference that sex differences stem from learned customs is problematic when one considers evidence of differential pain behaviors in male and female newborns $(7,8)$, despite no clear evidence of associated sex differences in neurocortical responses to pain (9). These developmental findings suggest instead that females are more sensitive than are males to express pain behaviours, which I have previously argued may be an artefact of the unique social subecologies in which human males and females evolved, and the utility of expressing pain for regulating different types of relationships (10).
In addition to promoting self-awareness (eg, to attend to and to protect an injured body part) and learning (eg, to avoid dangerous stimuli $[11,12]$ ), pain suffering may have evolved, in part, to be facultatively available to sensory awareness so as to express pain behaviours to selective relationship partners. By expressing or advertising a conditional state of vulnerability to others, individuals may be able to convey the impression of trustworthiness for the ultimate function of assessing, strengthening and soliciting reliable (versus expedient) social support from intimate relationship partners $(10,13,14$; for similar models of sadness and depression, see references 15 to 17). Indeed, females naturally form fewer, more intimate and consolidated social networks than do males (18), which may favour the advertisement of trust cues via submissive behaviors in the form of appeasement gestures (eg, expressed compassion) and vulnerability displays, including more ubiquitous use of pain and related internalizing behaviours such as depressive and anxiety symptoms (10).

According to this model, more frequent interactions with intimate relationship partners are predicted to heighten at puberty, as a result of a natural history of male-biased philopatry (female emigration into one's husband's natal community), thereby placing females at greater risk for experiencing pain sensations and pain-causing ailments such as menstrual cramps (10). Developmental research supports this hypothesis by showing that sex differences in pain, depression and related somatic symptoms correspond to pubertal transition in girls (19). This thesis is, alas, currently only able to offer speculative ultimate and midlevel explanations of sex differences in pain; however, it does provide novel hypotheses on various proximate physiological and psychological pain-related mechanisms, particularly because they correspond to the regulation of interpersonal intimacy and broader social contextual factors that characterize prototypical relationship dynamics in males versus females.

\section{REFERENCES}

1. Aziz CB, Abdullah NMN. Sex differences in pain. Intern Med J 2005;4:87-93.

2. Berkley KJ. Sex differences in pain. Behav Brain Sci 1 997;20:371-80.

3. Berman S, Munakata J, Naliboff BD, et al. Gender differences in regional brain responses to visceral pressure in IBS patients. Eur J Pain 2000;4:157-72. 
4. Craft RM, Mogil JS, Aloisi AM. Sex differences in pain and analgesia: The role of gonadal hormones. Eur J Pain 2004;8:397-411.

5. Greenspan JD, Craft RM, LeResche L, et al. Studying sex and gender differences in pain and analgesia: A consensus report. Pain 2007;132:S26-45.

6. Tolin DF, Foa EB. Sex differences in trauma and posttraumatic stress disorder: A quantitative review of 25 years of research. Psych Bull 2006;132:959-92.

7. Fuller BF. Infant gender differences regarding acute established pain. Clin Nurs Res 2002;11:190-203

8. Guinsburg R, Peres C, Almeida MF, et al. Differences in pain expression between male and female newborn infants. Pain 2000;85:127-33

9. Bartocci M, Bergqvist LL, Lagercrantz $\mathrm{H}$, Anand KJS. Pain activates cortical areas in the preterm newborn brain. Pain 2006;122:109-17.

10. Vigil JM. A socio-relational framework of sex differences in the expression of emotion. Behav Brain Sci 2009;32:375-428.

11. Eccleston C, Crombez G. Pain demands attention: A cognitiveaffective model on the interruptive function of pain. Psych Bull 1999;125:356-66.
12. Fields H. State-dependent opioid control of pain. Nat Rev Neurosci 2004;5:565-75.

13. Craig KD. The social communication model of pain. Can Psychol 2009;50:22-32.

14. Williams AC. Facial expression of pain: An evolutionary account. Behav Brain Sci 2002;25:439-55.

15. Hagen EH. The bargaining model of depression. In: Hammerstein P, ed. Genetic and Cultural Evolution of Cooperation. Cambridge: MIT Press, 2003:95-123.

16. Vigil JM. Sex differences in affect behaviors, desired social responses, and accuracy at understanding the social desires of other people. Evol Psychol 2008;6:506-22.

17. Watson PJ, Andrews PW. Toward a revised evolutionary adaptationist analysis of depression: The social navigation hypothesis. J Affect Disord 2002;72:1-14.

18. Rose AJ, Rudolph KD. A review of sex differences in peer relationship processes: Potential trade-offs for the emotional and behavioral development of girls and boys. Psych Bull 2006;132:98-131.

19. LeReschea L, Manclb LA, Drangsholta MT, Saundersc K, Von Korff M. Relationship of pain and symptoms to pubertal development in adolescents. Pain 2005;118:201-9. 


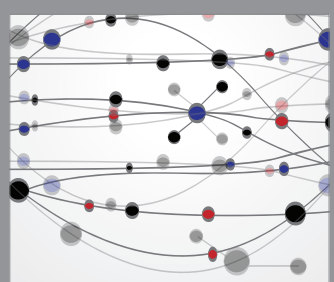

The Scientific World Journal
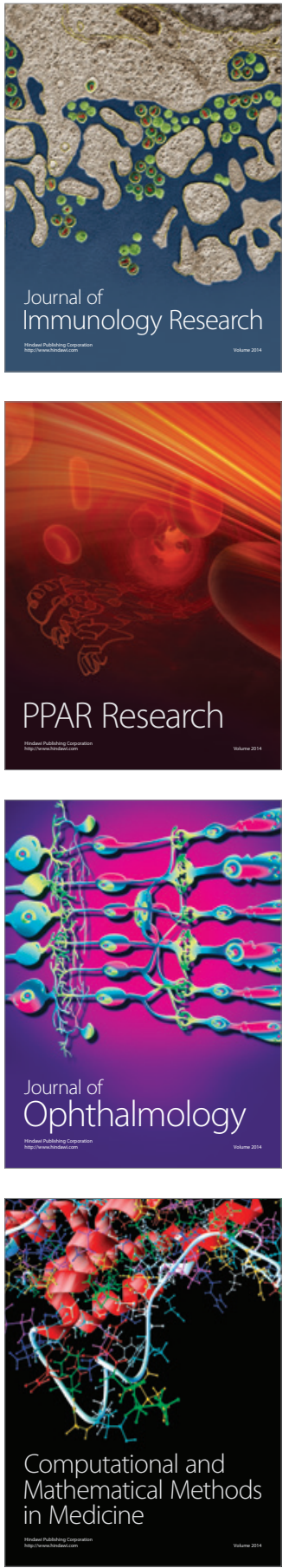

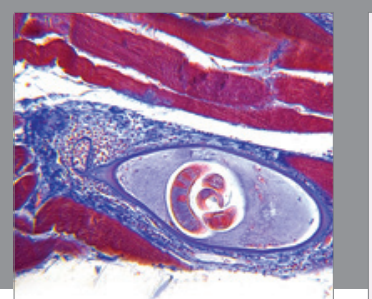

Gastroenterology Research and Practice

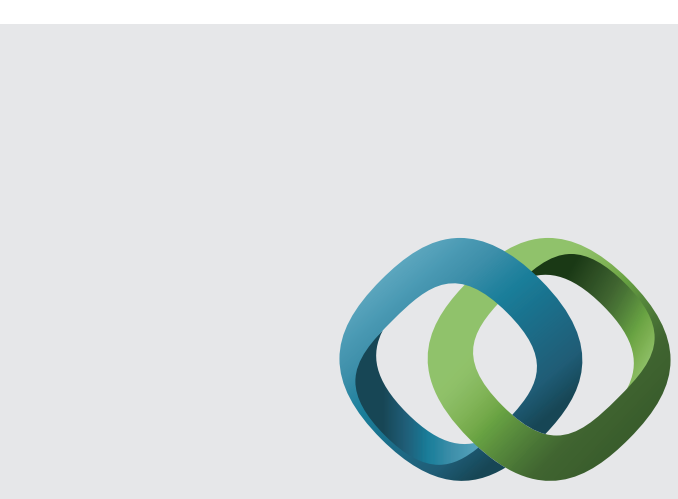

\section{Hindawi}

Submit your manuscripts at

http://www.hindawi.com
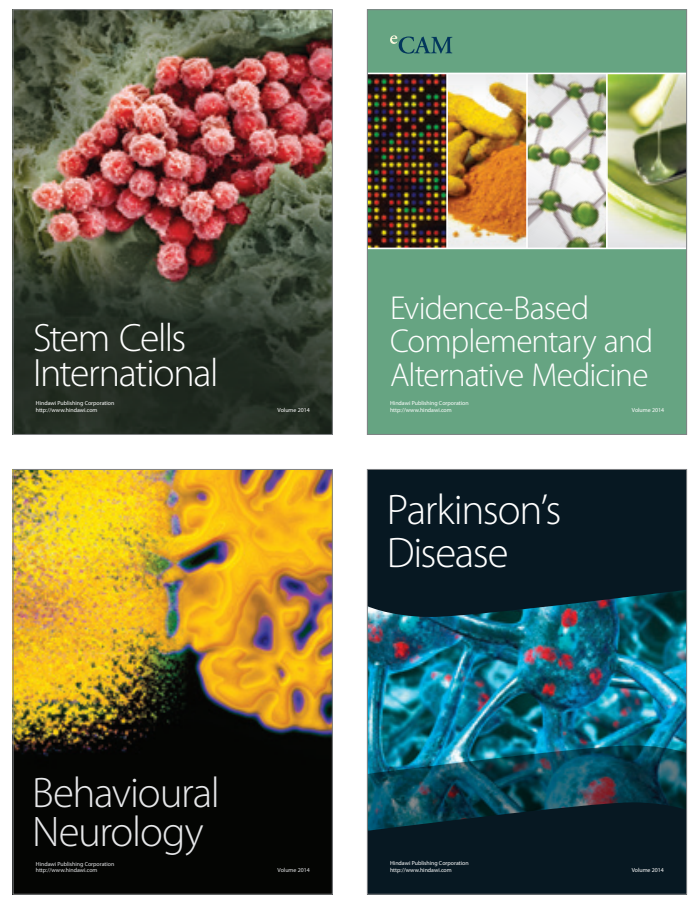
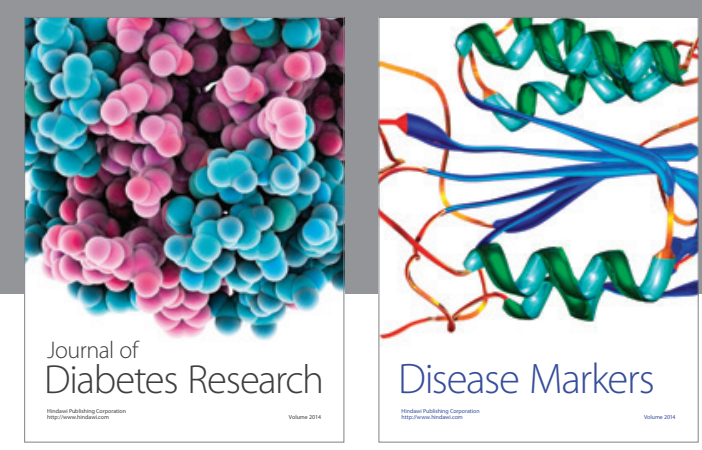

Disease Markers
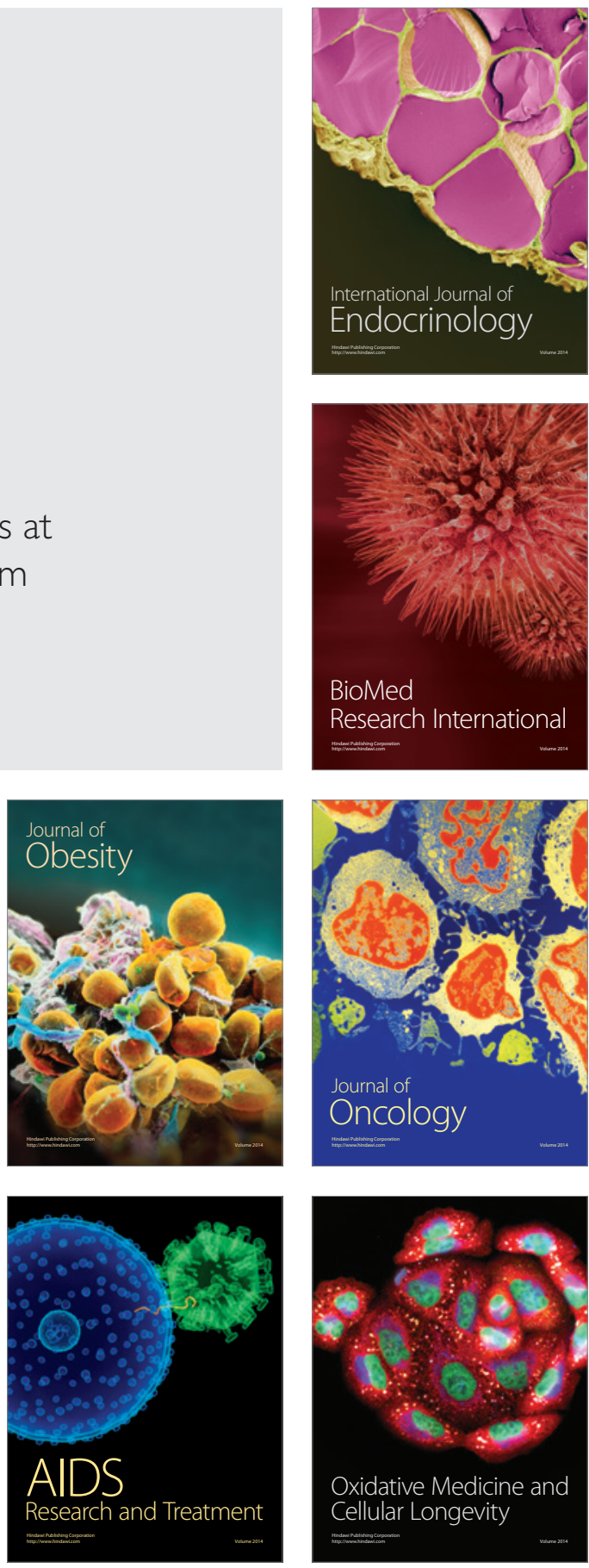